\title{
GERMINAÇÃO DE SEMENTES E CRESCIMENTO DE PLÂNTULAS DE DIFERENTES PROGÊNIES DE Euterpe edulis MART. ${ }^{1}$
}

\author{
Maisa Pimentel Martins-Corder ${ }^{2}$ e Cleber Witt Saldanha ${ }^{3}$
}

\begin{abstract}
RESUMO - O palmiteiro (Euterpe edulis Mart.) é uma espécie característica da Mata Atlântica, sendo conhecida pela produção de palmito. É uma palmeira com grande potencial para o manejo em regime de rendimento sustentável, e seus frutos são consumidos amplamente pela fauna. A propagação do palmiteiro através de sementes torna-se fator determinante na produção de mudas de qualidade para a manutenção de populações sustentáveis. O presente trabalho, realizado no Laboratório de Biotecnologia Florestal da Universidade Federal de Santa Maria, teve como objetivo avaliar a germinação e o crescimento inicial de 15 progênies de palmiteiro. $O$ delineamento experimental foi em blocos casualizados, com quatro repetições e 15 tratamentos (progênies) distribuídos em parcelas com 10 tubetes, contendo duas sementes por tubete. Foram analisadas as características: porcentagem de germinação de sementes; porcentagem de sobrevivência de mudas; diâmetro do colo; número de folhas e altura de plantas. Os resultados apontaram que as progênies de palmiteiro apresentaram maior variabilidade para a porcentagem de sobrevivência (amplitude de 26 a 58\% e média geral de 38\%), aos 210 dias. As mudas de palmiteiro mais vigorosas foram produzidas pela progênie $\left(\mathrm{P}_{12}\right)$, que exibiu melhores valores para porcentagem de sobrevivência $(\bar{x}=58 \%)$, altura $(\bar{x}=2,12 \mathrm{~cm})$, número de folhas $(\bar{x}=1,45)$ e diâmetro do colo $(\bar{x}=0,7 \mathrm{~cm})$. As progênies com menores taxas de sobrevivência $(\bar{x}=26 \%)$ foram mais tardias na iniciação da germinação e, conseqüentemente, apresentaram menor altura de plântulas $(\bar{x}=1,7 \mathrm{~cm})$. Portanto, lotes de sementes oriundas da população estudada de E. edulis deverão ser formados pelas progênies que mostraram homogeneidade dentre as características analisadas, no sentido de facilitar o manejo das mudas em condições de viveiro e também garantir maior uniformidade do material para o estabelecimento em condições de campo.
\end{abstract}

Palavras-chave: Palmiteiro, melhoramento genético e sobrevivência.

\section{SEED GERMINATION AND SEEDLING GROWTH OF DIFERENTES PROGENIES OF Euterpe edulis MART.}

\begin{abstract}
Heart-of-palm tree (Euterpe edulis Mart.) is a native species from Atlantic Forest, known by its production of palm heart. It is a palm with high potential to sustainable management and the fauna largely consumes its fruits. Heart-of-palm propagation through seeds is a determinant factor in the production of quality seedlings to the maintenance of sustainable populations. The objective of this study, conducted at Forest Biotechnology Laboratory from the Federal University of Santa Maria, was to evaluate the germination and initial growth of 15 progenies of heart-of-palm tree. The experimental design was completely randomized, with four replications and 15 treatments (progenies) distributed in 10 liner pots, with two seeds in each one. The following characteristics were analyzed: seed germination percentage, seedling survival percentage, stem diameter, leaf number and plant height. The results showed that heart-of-palm tree progenies had higher variability for survival percentage (ranging from 26 to $58 \%$ and average of $38 \%$ ), at 210 days. The most vigorous seedlings derived from provenance $P_{12}$, which showed better results for survival percentage $(\bar{x}=58 \%)$,
\end{abstract}

\footnotetext{
${ }^{1}$ Recebido em 15.01.2003 e aceito para publicação em 05.04.2006.

${ }^{2}$ Departamento de Ciências Florestais da Universidade Federal de Santa Maria (UFSM), Santa Maria-RS.E-mail:<lbfmaisa@smail.ufsm.br>.

${ }^{3}$ Programa de Pós-Graduação em Geomática da Universidade Federal de Santa Maria. E-mail: <clebersaldanha@ yahoo.com.br>.
} 
height $(\bar{x}=2.12 \mathrm{~cm})$, leaf number $(\bar{x}=1.45)$ and stem diameter $(\bar{x}=0.7 \mathrm{~cm})$. The provenances with low survival rates $(\bar{x}=26 \%)$ had more delayed seed germination and consequently showed lower seedling height $(\bar{x}=1.7 \mathrm{~cm})$. Hence, batches of seeds derived from the studied population of $\boldsymbol{E}$. edulis should be formed by the provenances showing homogeneity among the analyzed characteristics, in order to facilitate seedling management in nursery conditions, and also, guarantee a higher uniformity of the material to be established in field conditions.

Keywords: Heart-of-palm tree, genetic improvement and survival.

\section{INTRODUÇÃO}

A palmeira Euterpe edulis Martius pertence à família Palmae (Arecaceae), possui o estipe simples cresce até $20 \mathrm{~m}$ de altura, forma o palmito na base das folhas e ocorre naturalmente na Mata Atlântica. É popularmente conhecida como palmiteiro juçara, jiçara ou ripa (LORENZI e MELLO FILHO, 2001). O palmiteiro caracteriza-se por produzir palmito de excelente qualidade, com valor econômico elevado e amplamente consumido na alimentação humana, porém é uma planta que não rebrota na base e o corte implica sua morte (CARVALHO, 2003). No entanto, o palmiteiro é de extrema importância ecológica na cadeia alimentar do ecossistema florestal, pois apresenta altos níveis de interação com os animais e desempenha significativo papel na nutrição da fauna da Mata Atlântica, uma vez que seu fruto serve de alimento para aves e mamíferos, como roedores, marsupiais, primatas e morcegos (REIS e KAGEYAMA, 2000).

As populações foram drasticamente reduzidas devido à ação extrativista e ao corte indiscriminado do palmiteiro, sendo atualmente encontrado apenas em áreas protegidas da Mata Atlântica, principalmente em locais de difícil acesso (FANTINI et al., 1997). Essas ações extrativistas têm inviabilizado que a regeneração natural do palmiteiro seja suficiente para recompor a população original (REIS et al., 2000). Trata-se de uma espécie que tem sido comercialmente explorada e que pode ser cultivada em florestas nativas, permitindo sua conservação através de sistemas de enriquecimento e manejo sustentável (FANTINI et al., 1997). Dessa maneira, a propagação através de sementes torna-se fator determinante na produção de mudas para a manutenção de populações de palmiteiro.

Freqüentemente, as sementes de palmiteiro têm apresentado dificuldades para germinar, ou germinação lenta e desuniforme (BOVI e CARDOSO, 1976). Por se tratar de sementes recalcitrantes, a redução no teor de umidade abaixo de $28 \%$ ocasiona perda de viabilidade e, conseqüentemente, diminuição nas taxas de germinação (REIS et al., 1999); sementes viáveis iniciaram o processo germinativo em média aos 170 dias após a semeadura (CARVALHO, 1994). Negreiros e Perez (2004) constataram que sementes viáveis de E. edulis recém-coletadas possuíam $37 \%$ de umidade.

A instalação e manutenção de plantações sustentáveis de E. edulis, em condições naturais, exigem estudos relacionados aos aspectos silviculturais do palmiteiro (VENTURI e PAULILO, 1998), como estudos relacionados à geminação de sementes. Dentre esses aspectos em espécies florestais, por exemplo em Eucalyptus grandis, Mello e Oda (1997) relataram que o vigor germinativo foi qualitativamente essencial na produção de mudas, pois a variação entre progênies no crescimento inicial de plântulas afetou a operação de desbaste, favorecendo progênies com maior crescimento inicial. Freqüentemente, determinadas progênies podem apresentar maiores taxas de germinação de sementes e maior crescimento em altura e diâmetro do colo. Provavelmente, isso propiciaria maior possibilidade de ocupação e aproveitamento mais rápido do substrato em condições naturais, favorecendo o estabelecimento dessas progênies.

Desse modo, o presente estudo teve como objetivo avaliar o desempenho germinativo de sementes e o crescimento inicial de mudas de diferentes progênies de palmiteiro.

\section{MATERIAL E MÉTODOS}

Os frutos de palmiteiro foram colhidos em diferentes palmeiras desenvolvendo em uma propriedade particular de 30 ha, localizada na Floresta Estacional Decidual, em Santa Cruz do Sul (RS), na Depressão Central, com 29 $41^{\prime}$ ' " de latitude sul e 52 26 ' $46^{\prime \prime}$ de longitude oeste. A coleta foi individualizada por matriz, em que se coletaram 15 matrizes, originando as 15 progênies. Todos os frutos 
coletados apresentavam pericarpo roxo e umidade em torno de $42 \%$. Após o despolpamento, as sementes foram acondicionadas em sacos plásticos hermeticamente fechados e submetidos a tratamentos com os fungicidas Captan (4 g) e Benlate $(0,7 \mathrm{~g})$ para cada quilograma de frutos. As sementes continham $40 \%$ de umidade e foram posteriormente armazenadas em câmara fria a $5 \pm 2{ }^{\circ} \mathrm{C}$. Após um mês de armazenamento, realizou-se a semeadura das diferentes progênies de palmiteiro em tubetes de polietileno $\left(288 \mathrm{~cm}^{3}\right)$, sendo utilizado como substrato uma mistura de húmus, vermiculita e solo horizonte $\mathrm{B}$ (1:1:1). A formulação do substrato foi baseada em resultados de testes preliminares para germinação de palmiteiro. As plantas foram mantidas em condições de casa de vegetação durante todo o seu desenvolvimento, com irrigações diárias e temperatura de $26 \pm 2{ }^{\circ} \mathrm{C}$, conforme Brasil (1992). Este trabalho foi realizado no Laboratório de Biotecnologia Florestal na Universidade Federal de Santa Maria, em Santa Maria, RS.

O delineamento experimental utilizado foi de blocos casualizados, e os tratamentos constaram de 15 progênies, em quatro repetições. Foram utilizados 10 tubetes em cada parcela, contendo duas sementes por tubete, bem como avaliadas as porcentagens de germinação aos $60,90,120,150$ dias e de sobrevivência aos 180 e 210 dias após a semeadura, através do valor acumulado nas avaliações. Aos 210 dias, foram feitas as operações de raleio das mudas, deixando-se uma muda por recipiente. Aos 210 dias, realizaram-se as avaliações do crescimento das mudas, quando foram medidos o diâmetro do colo, a altura total e o número de folhas.

Nas análises de variância foram consideradas as características: porcentagem de sobrevivência, diâmetro do colo, altura total e número de folhas, cujos resultados de porcentagem de sobrevivência sofreram transformação em $\operatorname{arc}$ sen $o \sqrt{x}$. Altura de plântulas, diâmetro de colo, número de folhas e sobrevivência foram analisados pelo teste de Tukey no Sistema para Análises Estatísticas (ESTAT), programa desenvolvido pela Universidade do Estado de São Paulo - UNESP, de Jaboticabal.

\section{RESULTADOS E DISCUSSÃO}

Os resultados da porcentagem de germinação de sementes de palmiteiro aos 60, 90, 120 dias são apresentados na Tabela 1. Nove progênies de palmiteiro haviam começado o processo germinativo, sendo que a maior média de germinação foi da progênie $\mathrm{P}_{6}(3,9 \%)$, aos 60 dias. A progênie $P_{8}$ foi a mais tardia na iniciação, pois começou a germinação aos 90 dias. Observouse variabilidade na precocidade de germinação entre progênies. Trabalhos semelhantes realizados com palmeiras também constataram variações entre genótipos para a porcentagem de germinação (OLIVEIRA et al., 2003; CUNHA e JARDIM, 1995; REIS et al., 1992). A amplitude de variação da porcentagem de germinação foi de 0 a $4 \%$ (60 dias), 0 a $15 \%$ (90 dias), 3 a $25 \%$ (120 dias) e 14 a $56 \%$ (150 dias) (Tabela 1$)$.

Tabela 1 - Valores acumulados de porcentagem de germinação de progênies de palmiteiro (Euterpe edulis Mart.) procedentes de Santa Cruz do Sul, RS, respectivamente aos 60, 90, 120 e 150 dias

Table 1 - Accumulated values of germination percentage of hear-of-palm tree progenies (Euterpe edulis Mart.) derived from Santa Cruz do Sul (RS), at 60, 90, 120 and 150 days days after sowing

\begin{tabular}{|c|c|c|c|c|}
\hline \multirow[t]{2}{*}{ Progênie } & \multicolumn{4}{|c|}{ Porcentagem de Germinação } \\
\hline & 60 Dias & 90 Dias & 120 Dias & 150 Dias \\
\hline$P_{01}$ & 0,0 & 1,1 & 5,1 & 18,9 \\
\hline $\mathrm{P}_{02}$ & 0,7 & 8,9 & 25,3 & 55,6 \\
\hline $\mathrm{P}_{03}$ & 1,1 & 4,7 & 15,8 & 39,7 \\
\hline $\mathrm{P}_{04}$ & 0,0 & 0,8 & 12,8 & 56,4 \\
\hline $\mathrm{P}_{05}$ & 0,6 & 3,3 & 12,8 & 37,8 \\
\hline $\mathrm{P}_{06}$ & 3,9 & 7,8 & 20,8 & 43,9 \\
\hline $\mathrm{P}_{07}$ & 0,6 & 4,2 & 8,9 & 33,1 \\
\hline $\mathrm{P}_{08}$ & 0,0 & 0,0 & 3,1 & 13,9 \\
\hline $\mathrm{P}_{09}$ & 0,0 & 0,8 & 14,2 & 47,6 \\
\hline $\mathrm{P}_{10}$ & 0,0 & 1,5 & 13,2 & 41,0 \\
\hline $\mathrm{P}_{11}$ & 0,7 & 3,3 & 18,2 & 21,8 \\
\hline $\mathrm{P}_{12}$ & 1,5 & 15,0 & 25,0 & 46,7 \\
\hline $\mathrm{P}_{13}$ & 0,8 & 3,8 & 17,2 & 41,7 \\
\hline $\mathrm{P}_{14}$ & 0,0 & 2,1 & 5,3 & 28,8 \\
\hline $\mathrm{P}_{15}$ & 0,3 & 3,1 & 12,5 & 41,9 \\
\hline
\end{tabular}

R. Árvore, Viçosa-MG, v.30, n.5, p.693-699, 2006 
Na média, a taxa de germinação das sementes de diversas progênies de palmiteiro foi de $38 \%$, aos 150 dias (Tabela 1). Os maiores valores da porcentagem de germinação foram nas progênies $\mathrm{P}_{4}(56 \%), \mathrm{P}_{2}(55 \%), \mathrm{P}_{9}(48 \%)$ e $\mathrm{P}_{12}(47 \%)$ e o menor, em $\mathrm{P}_{8}(14 \%)$ (Tabela 1$)$.

Neste estudo, os valores obtidos da porcentagem de germinação foram semelhantes aos citados para a espécie. Em E. edulis, a taxa de germinação encontrada por Negreiros e Perez (2004) foi de - 44\%, aos 160 dias; por Andrade et al. (1999) - 73\%, aos 100 dias; e por Nodari et al. (1998) $-73 \%$, aos 180 dias. Provavelmente, as diferenças observadas na porcentagem de germinação das progênies de palmiteiro do presente estudo, aos 150 dias, sejam devidas aos componentes genéticos, pois os frutos foram colhidos no mesmo período e apresentavam índices de maturação semelhantes. As diferenças verificadas na germinação de Euterpe oleracea foram atribuídas aos componentes genéticos (MARTINS et al., 1999). Progênies de Euterpe oleracea tiveram diferenças genéticas para caracteres germinativos (OLIVEIRA et al., 2003). As diferenças genotípicas representaram um importante componente da variação total observada em todas as características de germinação em espécies florestais (YOUNG et al., 2000). Em Euterpe espiritosantensis, a germinação uniforme das sementes foi uma característica importante na formação de mudas, pois, quanto mais tempo a plântula levou para emergir na superfície do solo e permaneceu nos estádios iniciais de desenvolvimento, mais vulnerável esteve nas condições do meio (MARTINS et al., 2000). Variações no período germinativo entre genótipos de E. edulis foram associadas a uma estratégia adaptativa, possibilitando a entrada gradual de indivíduos no banco de plântulas (REIS et al., 1992).

Neste estudo não ocorreu ataque por fungos em razão provavelmente, do tratamento com fungicidas antes do armazenamento das sementes de palmiteiro. A manutenção dessas sementes com umidade elevada favorece a germinação, no entanto, o desenvolvimento de fungos e bactérias pode ocorrer nas sementes durante o armazenamento e ser prejudicial à germinação (QUEIROZ, 2000).

As progênies de palmiteiro diferiram significativamente quanto à porcentagem de sobrevivência de mudas. As maiores médias das progênies foram: $\mathrm{P}_{12}(58 \%), \mathrm{P}_{4}(55 \%)$, $\mathrm{P}_{13}(55 \%)$ e $\mathrm{P}_{9}(51 \%)$, aos 210 dias (Figura 1). As menores taxas de sobrevivência foram das progênies: $\mathrm{P}_{1}(32 \%)$ e $\mathrm{P}_{8}(26 \%)$, aos 210 dias. Na progênie $\mathrm{P}_{2}$ ocorreu redução de 5,8\% de indivíduos (plântulas), aos 210 dias, em relação ao valor de $56 \%$ observado aos 150 dias. As progênies $\mathrm{P}_{2}, \mathrm{P}_{3}, \mathrm{P}_{4}$ e $\mathrm{P}_{6}$ apresentaram valores máximos de germinação aos 150 dias, sendo que houve, entre essas progênies, mortalidade média de $3 \%$ aos 210 dias (Tabela 1 e Figura 1). Aos 210 dias, as progênies de palmiteiro $\left(P_{1}, P_{7}, P_{8}\right.$, $\mathrm{P}_{11}$ e $\mathrm{P}_{14}$ ) exibiram um acréscimo no número de plântulas de cerca de $10 \%$ em relação à porcentagem de germinação aos 150 dias, embora com os menores índices de germinação (Figura 1 e Tabela 1). No entanto, apesar das mais altas taxas de germinação, as progênies $\mathrm{P}_{12}$ e $\mathrm{P}_{13}$ também apresentaram acréscimo no número de plântulas emergentes entre 150 e 210 dias. O rápido crescimento possibilitou às plântulas de palmiteiro mais rápido aproveitamento de reservas nutricionais e hídricas do solo e, consequientemente, realizar a fotossíntese, aumentando a chance de seu rápido estabelecimento (ANDRADE et al., 1996). Verificou-se, portanto, que a germinação ocorreu de forma lenta em progênies do palmiteiro em estudo, as quais apresentaram as menores porcentagens de germinação, não tendo mortalidade a partir dos 150 dias.

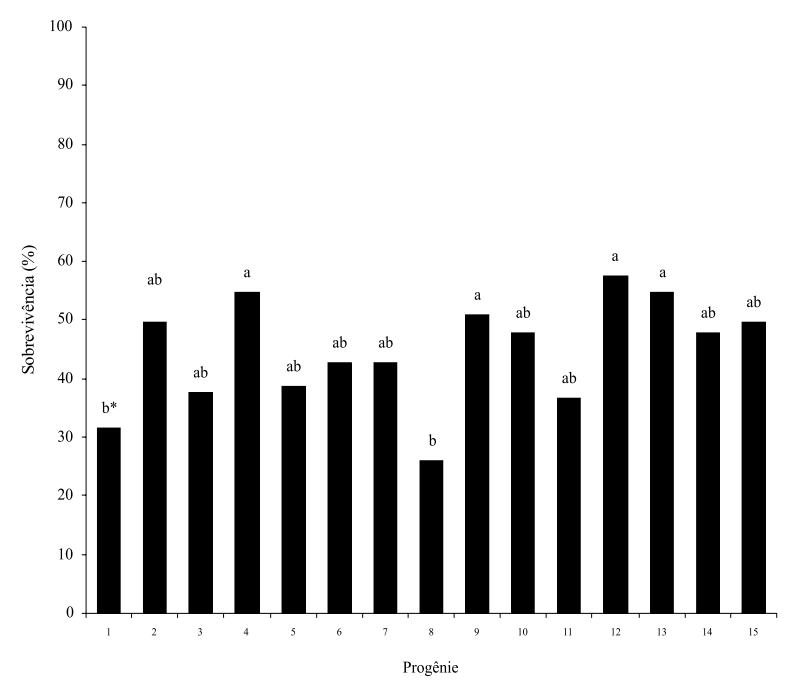

* Progênies com médias não ligadas pela mesma letra diferem pelo teste de Tukey a $1 \%$ de probabilidade de erro, quanto à porcentagem de sobrevivência.

Figura 1 - Valores acumulados de porcentagem de sobrevivência de progênies de palmiteiro (Euterpe edulis Mart.) procedentes de Santa Cruz do Sul, RS, aos 210 dias. Coeficiente de variação de sobrevivência (CV\%): $17,2 \%$.

Figure 1-Accumulated values of survival percentage of heartof-palm tree progenies (Euterpe edulis Mart.) derived from Santa Cruz do Sul (RS), at 210 days days after sowing. Coefficient of variation for survival (CV\%): $17.2 \%$. 
As sementes de palmiteiro do presente estudo que levaram um tempo maior para germinar deram origem a plântulas menos vigorosas, com visíveis desordens de natureza fisiológica. Provavelmente, problemas relacionados ao cruzamento entre indivíduos aparentados levaram à produção de plântulas frágeis e vulneráveis, fato conhecido como depressão por endogamia. A constante redução da base genética, em conseqüência da intensa exploração dos palmitais, diminuiu o tamanho da população e o número de indivíduos adultos, aumentando a chance de cruzamentos entre indivíduos aparentados. Freqüentemente, as descendências resultantes de cruzamentos endogâmicos mostram reduzidos índices de sobrevivência (WRIGHT, 1976). Conforme MartinsCorder et al. (1998), em Eucalyptus globulus spp. globulus a baixa taxa de germinação e a produção de plântulas anormais possivelmente foram em função da elevada taxa de autofecundação.

Tabela 2 - Valores médios de altura, diâmetro do colo e número de folhas de plântulas de palmiteiro (Euterpe edulis Mart.) de progênies procedentes do município de Santa Cruz do Sul, RS, aos 210 dias após a semeadura

Table 2 - Average values of the height, stem diameter and leaf number of heart-of-palm tree seedlings (Euterpe edulis Mart.) of progenies derived from the municipal district of Santa Cruz do Sul (RS), at 210 days after sowing

\begin{tabular}{cccc}
\hline Progênie & $\begin{array}{c}\text { Altura } \\
(\mathrm{cm})\end{array}$ & $\begin{array}{c}\text { Diâmetro } \\
\text { do Colo }(\mathrm{cm})\end{array}$ & $\begin{array}{c}\text { Número } \\
\text { de Folhas }\end{array}$ \\
\hline $\mathrm{P}_{01}$ & $1,72 \mathrm{~b} *$ & $0,62 \mathrm{~b}$ & $1,33 \mathrm{ab}$ \\
$\mathrm{P}_{02}$ & $2,05 \mathrm{ab}$ & $0,73 \mathrm{a}$ & $1,45 \mathrm{ab}$ \\
$\mathrm{P}_{03}$ & $1,99 \mathrm{ab}$ & $0,71 \mathrm{ab}$ & $1,39 \mathrm{ab}$ \\
$\mathrm{P}_{04}$ & $1,94 \mathrm{ab}$ & $0,69 \mathrm{ab}$ & $1,35 \mathrm{ab}$ \\
$\mathrm{P}_{05}$ & $1,89 \mathrm{ab}$ & $0,69 \mathrm{ab}$ & $1,32 \mathrm{ab}$ \\
$\mathrm{P}_{06}$ & $2,01 \mathrm{ab}$ & $0,7 \mathrm{ab}$ & $1,34 \mathrm{ab}$ \\
$\mathrm{P}_{07}$ & $1,8 \mathrm{ab}$ & $0,67 \mathrm{ab}$ & $1,33 \mathrm{ab}$ \\
$\mathrm{P}_{08}$ & $1,7 \mathrm{~b}$ & $0,68 \mathrm{ab}$ & $1,08 \mathrm{~b}$ \\
$\mathrm{P}_{09}$ & $1,92 \mathrm{ab}$ & $0,64 \mathrm{ab}$ & $1,30 \mathrm{ab}$ \\
$\mathrm{P}_{10}$ & $1,81 \mathrm{ab}$ & $0,68 \mathrm{ab}$ & $1,36 \mathrm{ab}$ \\
$\mathrm{P}_{11}$ & $1,85 \mathrm{ab}$ & $0,67 \mathrm{ab}$ & $1,37 \mathrm{ab}$ \\
$\mathrm{P}_{12}$ & $2,12 \mathrm{a}$ & $0,66 \mathrm{ab}$ & $1,42 \mathrm{a}$ \\
$\mathrm{P}_{13}$ & $2,09 \mathrm{a}$ & $0,7 \mathrm{ab}$ & $1,40 \mathrm{a}$ \\
$\mathrm{P}_{14}$ & $1,94 \mathrm{ab}$ & $0,73 \mathrm{a}$ & $1,26 \mathrm{ab}$ \\
$\mathrm{P}_{15}$ & $1,94 \mathrm{ab}$ & $0,68 \mathrm{ab}$ & $1,39 \mathrm{ab}$ \\
\hline Média & 1,92 & 0,68 & 1,34 \\
\hline $\mathrm{CV}^{\mathrm{a}}(\%)$ & 8,3 & 5,7 & 9,4 \\
\hline
\end{tabular}

* Progênies com médias não ligadas por mesma letra diferem pelo

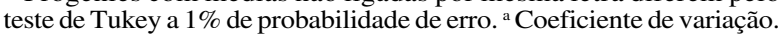

As progênies de palmiteiro estudadas apresentaram diferenças significativas com relação às características de altura de plântulas, diâmetro do colo e número de folhas (Tabela 2). A média geral para altura de plântulas foi de $1,92 \mathrm{~cm}$, em que as progênies $\mathrm{P}_{12}(2,12 \mathrm{~cm})$ e $\mathrm{P}_{13}(2,09 \mathrm{~cm})$ tiveram as maiores médias. As menores médias de altura foram das progênies que exibiram as menores taxas de sobrevivência $\left(\mathrm{P}_{1}\right.$ e $\left.\mathrm{P}_{8}\right)$ e foram mais tardias na iniciação da germinação.

As progênies $\mathrm{P}_{12}$ e $\mathrm{P}_{13}$ de palmiteiro em estudo apresentaram as melhores médias de altura e número de folhas. Tem sido relatado que a eficiência na captação de energia luminosa para a fotossíntese permite às plantas a obtenção de energia química, sendo crucial para e seu pleno desenvolvimento (LARCHER, 2000).

As progênies de palmiteiro do presente estudo apresentaram variação quanto ao diâmetro do colo, em que a amplitude de variação foi de 0,73 a $0,62 \mathrm{~cm}$ (Tabela 2). Em testes de progênies de palmiteiro, o diâmetro do colo de plântulas é uma característica adequada para indicar a diferenciação entre genótipos (NODARI e FANTINI, 2000).

No presente estudo, o coeficiente de variação reduzido $(5,7 \%)$ permitiu atribuir a variação do diâmetro do colo às diferenças genéticas entre as progênies de palmiteiro. De acordo com Nodari e Fantini (2000), quando esse coeficiente é menor que $20 \%$ a variação é devida a diferenças genéticas entre as progênies de palmiteiro.

É preferível que lotes de sementes de palmiteiro sejam constituídos com progênies que apresentem homogeneidade nas características de porcentagem de germinação e sobrevivência, altura, diâmetro do colo e número de folhas para favorecer as operações de viveiro. Em Eucalyptus globulus spp. Globulus, uma germinação mais uniforme ressultou para plântulas mais vigorosas sem alteração na diversidade genética total (MARTINS-CORDER et al., 1998).

A quantidade de folhas em plântulas de palmiteiro pode estar diretamente relacionada com a sobrevivência das plântulas em condições naturais, pois, quanto maior o número de folhas fotossintetizantes, maior a produção de componentes associados ao crescimento das plântulas. No presente estudo, essa característica apresentou diferenças significativas entre as progênies analisadas (Tabela 2). A progênie $\mathrm{P}_{12}(1,45)$ e a $\mathrm{P}_{13}(1,42)$ tiveram as melhores médias do número de folhas e a

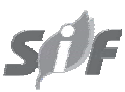

R. Árvore, Viçosa-MG, v.30, n.5, p.693-699, 2006 
$\mathrm{P}_{8}(1,08)$, a menor média, aos 210 dias. O número de folhas pode ser um bom indicativo do vigor das plântulas, refletindo no desempenho em condições naturais, pois mudas mais vigorosa apresentam menores índices de mortalidade e são mais aptas para o estabelecimento. Plântulas de E. edulis com número de folhas superior foram favorecidas no crescimento, pois a produção fotossintética excedeu a matéria dispendida na respiração (VENTURI e PAULILO, 1998).

Em termos práticos, lotes de sementes da população estudada deveriam ser formados por progênies que apresentarem homogeneidade das características analisadas, no sentido de facilitar o manejo das mudas em condições de viveiro e garantir maior uniformidade do material.

\section{CONCLUSÕES}

As mudas de palmiteiro produzidas pelas progênies com maiores médias de porcentagem de sobrevivência apresentaram maiores médias de altura, número de folhas e diâmetro do colo. Contrariamente, as progênies com menores taxas de sobrevivência exibiram menores médias dessas características e foram mais tardias na iniciação da germinação.

\section{AGRADECIMENTOS}

À Engenheira Florestal Veronilda R. Bonet de Quadros, pela colaboração na realização deste trabalho.

\section{REFERÊNCIAS BIBLIOGRÁFICAS}

ANDRADE, C. S. et al. Reavaliação do efeito do substrato e da temperatura na germinação de sementes de palmiteiro (Euterpe edulis Mart.). Revista Árvore, v. 23, n. 3, p. 279-283, 1999.

ANDRADE, C. S.; VENTURI, S.; PAULILO, M. T. S. Efeito do tamanho das sementes de Euterpe edulis sobre a emergência e crescimento inicial. Revista Brasileira de Sementes, v. 18, n. 2, p. 225-231, 1996.

BANZATTO, D. A. et al. Programa ESTAT (Sistema para Análises Estatísticas). Jaboticabal: Universidade Estadual de São Paulo, 1989.

BOVI, M. L. A.; CARDOSO, M. Germinação de Sementes de Palmiteiro (Euterpe edulis Mart.) I. Bragantia , v. 35, n. 6, p. 23-29, 1976.
BRASIL. Ministério da Agricultura e da Reforma Agrária. Regras para a análise de sementes. Brasília: SNDA/DNDV/CLAV, 1992.365p.

CARVALHO, P. E. R. Espécies arbóreas brasileiras. Colombo: Embrapa Florestas, 2003. 1039 p.

CARVALHO. P. E. R. Espécies florestais brasileiras: recomendações silviculturais, potencialidades e uso da madeira. Colombo: Embrapa Florestas, 1994. 640p.

CUNHA, A. C. C.; JARDIM, M. A. G. Avaliação do potencial germinativo em açaí (Euterpe oleracea Mart.) variedades preto, branco e espada. Boletim do Museu Paraense Emílio Goeldi, v. 11, n. 1, p. 55-60, 1995.

FANTINI, A. C. et al. Estimativa da produção de palmito em plantas de palmiteiro (Euterpe edulis Martius) a partir de características fenotípicas. Revista Árvore, v. 21, n. 1, p. 49-57, 1997.

LARCHER, W. Ecofisiologia vegetal. São Carlos: RIMA, 2000. 531 p.

LORENZI, H.; MELLO FILHO, L. E. As plantas tropicais de R. Burle Max. São Paulo: Instituto Plantarum de Estudos da Flora, 2001. 504p.

MARTINS, C. C. et al. Influência do peso das sementes de palmito-vermelho (Euterpe espiritosantensis Fernandes) na porcentagem e na velocidade de germinação. Revista Brasileira de Sementes, v. 22, n. 1, p. 47-53, 2000.

MARTINS, C. C. et al. Teores de água crítico e letal para sementes de açaí (Euterpe oleracea Mart. - Palmae). Revista Brasileira de Sementes, v. 21, n. 1, p. 125-132, 1999.

MARTINS-CORDER, M. P. et al. Genetic diversity of three size classes of seeds of Eucalyptus globulus ssp. globulus. Silvae Genetica, v. 47, n. 1, p. 6-14, 1998.

MELLO, E. J.; ODA, S. Variação no vigor de sementes e no crescimento inicial de diferentes progênies de Eucalyptus grandis. In: IUFRO CONFERENCE ON SILVICULTUREAND IMPROVEMENT OF EUCALYPT. 1997, Colombo. Proceedings... Colombo: Embrapa, 1997. v. 3, p. 411-417. 
NEGREIROS, G. F.; PEREZ, S. C. J. G. A. Resposta fisiológica de sementes de palmeiras ao envelhecimento acelerado. Pesquisa Agropecuária Brasileira, v. 39, n. 4, p. 391-396, 2004.

NODARI, R. O.; FANTINI, A. C. Melhoramento genético do palmiteiro. Sellowia, v. 49-52, p. $163-188,2000$.

NODARI, R. O. et al. Conservação de frutos de palmiteiro (Euterpe edulis Martius) sob diferentes condições de armazenamento. Revista Árvore, v. 22, n. 1, p.1-10, 1998.

OLIVEIRA, M. S. P. et al. Parâmetros genéticos para caracteres germinativos em vinte progênies de açaizeiro promissores para palmito. Boletim de Pesquisa Florestal, v. 46, p. 105-113, 2003.

QUEIROZ, M. H. Biologia do fruto, da semente e da germinação do palmiteiro (Euterpe edulis Martius). Sellowia, v. 49, n. 52, p. 39-49, 2000.

REIS, A.; KAGEYAMA, P. Y. Dispersão de sementes de Euterpe edulis Martius Palmae. Sellowia, v. 49-52, p. 60-92, 2000.
REIS, M. S. et al. Distribuição geográfica e situação atual das populações na área de ocorrência de Euterpe edulis Martius. Sellowia, v. 49, n. 52, p. 324-335, 2000.

REIS, M. S.; FRANCHINI, R. G.; FANTINI, A. C. Variação no período germinativo em sementes de Euterpe edulis Martius procedentes da região de Morretes-PR. Revista do Instituto Florestal, v. 4, p. 1252-1255, 1992.

REIS, A. et al. Efeito de diferentes níveis de dessecamento na germinação de sementes de Euterpe edulis Martius Arecaceae. Insula, v. 28, p. 31-42, 1999.

VENTURI, S.; PAULILO, M. T. S. Esgotamento das reservas na semente de Euterpe edulis Mart. e efeito da nutrição mineral nas plântulas. Acta Botanica Brasilica, v. 12, n. 3, p. 215-220, 1998.

WRIGHT, J. W. Introduction to Forest genetics. New York: Academic Press, 1976.

YOUNG, A.; BOSHIER, D.; BOYLE, T. (Eds.). Forest conservation genetics. Melbourne: CSIRO Publishing, 2000. p. 197-213. 